\title{
An automated gas exchange tank for determining gas transfer velocities in natural seawater samples
}

\author{
K. Schneider-Zapp ${ }^{1}$, M. E. Salter ${ }^{2}$, and R. C. Upstill-Goddard ${ }^{1}$ \\ ${ }^{1}$ Ocean Research Group, School of Marine Science and Technology, Newcastle University, Newcastle upon Tyne, UK \\ ${ }^{2}$ Department of Applied Environmental Science, Stockholm University, Stockholm, Sweden \\ Correspondence to: K. Schneider-Zapp (klaus.schneider-zapp@ncl.ac.uk)
}

Received: 10 January 2014 - Published in Ocean Sci. Discuss.: 21 February 2014

Revised: 20 May 2014 - Accepted: 24 May 2014 - Published: 3 July 2014

\begin{abstract}
In order to advance understanding of the role of seawater surfactants in the air-sea exchange of climatically active trace gases via suppression of the gas transfer velocity $\left(k_{\mathrm{w}}\right)$, we constructed a fully automated, closed air-water gas exchange tank and coupled analytical system. The system allows water-side turbulence in the tank to be precisely controlled with an electronically operated baffle. Two coupled gas chromatographs and an integral equilibrator, connected to the tank in a continuous gas-tight system, allow temporal changes in the partial pressures of $\mathrm{SF}_{6}, \mathrm{CH}_{4}$ and $\mathrm{N}_{2} \mathrm{O}$ to be measured simultaneously in the tank water and headspace at multiple turbulence settings, during a typical experimental run of $3.25 \mathrm{~h}$. PC software developed by the authors controls all operations and data acquisition, enabling the optimisation of experimental conditions with high reproducibility. The use of three gases allows three independent estimates of $k_{\mathrm{w}}$ for each turbulence setting; these values are subsequently normalised to a constant Schmidt number for direct comparison. The normalised $k_{\mathrm{w}}$ estimates show close agreement. Repeated experiments with Milli-Q water demonstrate a typical measurement accuracy of $4 \%$ for $k_{\mathrm{w}}$. Experiments with natural seawater show that the system clearly resolves the effects on $k_{\mathrm{w}}$ of spatial and temporal trends in natural surfactant activity. The system is an effective tool with which to probe the relationships between $k_{\mathrm{w}}$, surfactant activity and biogeochemical indices of primary productivity, and should assist in providing valuable new insights into the air-sea gas exchange process.
\end{abstract}

\section{Introduction}

Air-sea gas exchange is a critical global process, providing the fundamental link between reactive trace gas production and consumption in the oceans and global atmospheric processes. For example, the oceans are the largest single sink for tropospheric carbon dioxide $\left(\mathrm{CO}_{2}\right)$ (Khatiwala et al., 2009), contribute around one-third of tropospheric nitrous oxide $\left(\mathrm{N}_{2} \mathrm{O}\right)$ (IPCC, 2007) and make significant contributions to the global biogeochemical budgets of several other climateactive gases including methane $\left(\mathrm{CH}_{4}\right)$, carbon monoxide (CO), dimethyl sulfide $\left(\mathrm{CH}_{3} \mathrm{SCH}_{3}\right)$ and some other sulfur gases, and a range of halocarbons and hydrocarbons (UpstillGoddard, 2011). Understanding the physical and biogeochemical controls of air-sea gas exchange is therefore necessary for establishing biogeochemical models for predicting regional- and global-scale trace gas fluxes and feedbacks.

For a sparingly soluble gas, which applies to almost all gases of global biogeochemical interest, the flux $F$ (in mol cm $\mathrm{cm}^{-2} \mathrm{~h}^{-1}$ ) across the air-sea interface can be considered as a diffusion-limited process in a typically $20 \mu \mathrm{m}$ to $200 \mu \mathrm{m}$ thick "diffusive sub-layer" on the water side of the interface (Jähne, 2009). It is written as the product of the driving force, i.e. its concentration difference between air $C_{\mathrm{a}}$ and sea water $C_{\mathrm{W}}\left(\right.$ in $\mathrm{mol} \mathrm{cm} \mathrm{cm}^{-3}$ ), and the air-sea gas transfer velocity $k_{\mathrm{W}}$ (in $\mathrm{cm} \mathrm{h}^{-1}$ ):

$F=k_{\mathrm{w}}\left(\alpha C_{\mathrm{a}}-C_{\mathrm{w}}\right)$,

where $\alpha$ is the Ostwald solubility coefficient. Similar equations apply to the exchange of heat and momentum. The concentration difference term $\left(\alpha C_{\mathrm{a}}-C_{\mathrm{w}}\right)$ can be directly measured quite routinely but $k_{\mathrm{w}}$ cannot. Moreover, the magnitude 
of $k_{\mathrm{w}}$ varies with the degree of near-surface turbulence; increasing turbulence reduces the depth of the diffusive sublayer, resulting in an increase in $k_{\mathrm{w}}$. Indirect approaches are therefore required to estimate $k_{\mathrm{W}}$ in situ and evaluate its variability in response to environmental forcing functions generating turbulence. One often-used method for in situ measurement is the so-called "dual tracer technique", which measures the relative rates of evasion to air of two purposefully released, inert volatile tracers: sulfur hexafluoride $\left(\mathrm{SF}_{6}\right)$ and helium-3 $\left({ }^{3} \mathrm{He}\right)$. Temporal changes in the ratio of their seawater concentrations, typically measured over 24 to $48 \mathrm{~h}$ time intervals, are used to derive $k_{\mathrm{w}}$ estimates which are then scaled to corresponding values for $\mathrm{CO}_{2}$ and other reactive trace gases of interest, using diffusivity-based relationships (Wanninkhof et al., 1993, 1997; Watson et al., 1991; Nightingale et al., 2000). The dual tracer technique is, however, time-consuming, logistically complex and expensive, and it provides little, if any, information on the spatiotemporal variability of $k_{\mathrm{w}}$. Moreover, when the dual tracer $k_{\mathrm{w}}$ data are plotted against wind speed as the primary driver of turbulence, they show a high degree of scatter. Indeed, uncertainty over $k_{\mathrm{W}}$ variability presents one of the greatest challenges to quantifying the net global air-sea exchange of $\mathrm{CO}_{2}$ (Takahashi et al., 2009). While a recent analysis shows that around one half of this uncertainty may be ascribed to experimental and measurement errors inherent in the dual tracer technique (Asher, 2009), this still leaves significant $k_{\mathrm{w}}$ variability unaccounted for. This remaining variability reflects other environmental forcing functions in addition to wind speed, including wind fetch, atmospheric stability, sea state, wave breaking, white capping and bubble bursting, sea surface temperature, rain and the presence of surfactants and other organics (Upstill-Goddard, 2006, 2011).

Surfactants are well known to greatly suppress $k_{\mathrm{W}}$ and consequently the rate of air-sea gas exchange, mostly by modifying sea surface hydrodynamics and hence turbulent energy transfer, but also by forming a monolayer physical barrier (McKenna and McGillis, 2004). Natural surfactants are ubiquitous in seawater, being primarily phytoplankton exudates such as polysaccharides, proteins and lipids, and their degradation products (Gašparović, 2012; Zutić et al., 1981), with additional sources via terrestrial inputs of humic and fulvic acids to coastal waters. Spatio-temporal distributions are therefore highly variable. Surfactants tend to be enriched in the diffusive sub-layer relative to underlying water up to high wind speeds (Wurl et al., 2011) but their precise effects on $k_{\mathrm{W}}$ are not well characterised, studies with natural seawaters being comparatively scarce. Most data have been derived using wind flumes and/or open exchange tanks in the laboratory (e.g. Goldman et al., 1988; Frew, 1997; Bock et al., 1999); this in part reflects the specialised nature of the analyses and a need to simplify experiments by using single, "model surfactants" in controlled conditions. While deliberate releases of man-made surfactant in tandem with the dual tracer technique have yielded some information on potential surfactant effects in situ (Salter et al., 2011), practical considerations currently preclude isolating the effects on $k_{\mathrm{w}}$ of natural surfactant levels during field experiments. This makes recourse to laboratory-based experiments inescapable.

In order to make further progress in this regard, we have devised a laboratory procedure that enables us to directly evaluate the contrast in $k_{\mathrm{w}}$ between natural seawaters of varying surfactant content under controlled and reproducible conditions of turbulence. To simplify the system, we generate water-side turbulence, allowing us to concentrate on the important aspects of comparative $k_{\mathrm{w}}$ measurements at constant turbulence and avoiding unnecessary complication of the system. This simplifies process-understanding and also overcomes difficulties associated with simulating wind-induced turbulence in a laboratory. Even though the absolute $k_{\mathrm{w}}$ values may not be strictly comparable to in situ conditions, this simplification is wholly adequate to achieve our goal of comparative $k_{\mathrm{w}}$ measurements at constant turbulence, and is an important step in understanding more completely the relationships between surfactants, turbulence and $k_{\mathrm{w}}$. Once this is established, more elaborate experiments in wind-wave facilities can provide valuable supplementary information. By measuring wave spectra in the tank, a record of the (temporal) wave field is available for each measurement, facilitating further comparison of experimental conditions between runs.

Our system uses a sealed laboratory gas exchange tank with integral water equilibrator. The partial pressures of experimental gases $\left(\mathrm{SF}_{6}, \mathrm{CH}_{4}\right.$ and $\left.\mathrm{N}_{2} \mathrm{O}\right)$ in the water and air phases of the system are measured using gas chromatography. Turbulence in the tank can be routinely selected and modified such that inter-sample differences in $k_{\mathrm{w}}$ exclusively reflect differences in sample surfactant content, something that cannot currently be achieved through field experiments.

\section{System design}

\subsection{Prior considerations}

We previously used a sealed gas exchange tank for examining the microbial controls of air-sea gas transfer (UpstillGoddard et al., 2003). This featured semi-automated analysis of the tank headspace gases $\left(\mathrm{SF}_{6}\right.$ and $\left.\mathrm{CH}_{4}\right)$ but the water phase sampling required manual operation and large sample volumes, necessitating large and cumulative volume corrections, and turbulence control was comparatively rudimentary. Analytical uncertainty was therefore high but experimental reproducibility and accuracy were not rigorously assessed. Overall system reliability was also rather variable. To adequately resolve inter-sample differences in $k_{\mathrm{w}}$ due to variability in surfactant content demands a redesigned system with vastly improved performance and flexibility. An important aspect of the system described here is its full automation. PC control software developed by the authors controls all operations and data acquisition. This is a key aspect of the system 
because it guarantees that all experiments are run under identical conditions, free of operator-induced variability. It also facilitates the optimisation of experimental run times, which is critical for surfactant-focused work because it is essential to preserve sample integrity when several samples have been collected along lateral seawater transects, for example. Natural surfactants can degrade rapidly and significantly on storage. Such changes are variable and can be difficult to predict due to differences in organic composition between water samples (Schneider-Zapp et al., 2013). Consequently, when sample storage is unavoidable it should be minimised as far as is practically possible.

\subsection{Selection of experimental gases}

The use of $\mathrm{SF}_{6}, \mathrm{CH}_{4}$ and $\mathrm{N}_{2} \mathrm{O}$ in the gas exchange experiments is based on our prior experience with them, in particular their ease of analysis, but most importantly because of their relevance in the context of air-sea gas exchange and global biogeochemistry. $\mathrm{SF}_{6}$ is inert and is essentially all man-made, although there is a small geological source (Harnisch and Eisenhauer, 1998), and it is routinely used for estimating $k_{\mathrm{w}}$ in situ (Wanninkhof et al., 1993, 1997; Watson et al., 1991; Nightingale et al., 2000). $\mathrm{CH}_{4}$ and $\mathrm{N}_{2} \mathrm{O}$ both have significant marine sources and sinks, are infrared active and have long atmospheric lifetimes (IPCC, 2007). $\mathrm{N}_{2} \mathrm{O}$ is also involved in stratospheric $\mathrm{O}_{3}$ regulation via $\mathrm{NO}_{\mathrm{x}}$ generation (Nevison and Holland, 1997) and $\mathrm{CH}_{4}$ participates in stratospheric water formation and in the photochemical regulation of tropospheric $\mathrm{OH}$ and $\mathrm{O}_{3}$ (Crutzen and Zimmermann, 1991). Both gases are currently increasing in the troposphere, but at variable rates that are not well understood (Dlugokencky et al., 1998, 2001; Khalil, 1993; Prinn et al., 1990; Rigby et al., 2008). Quantifying the constraints on their air-sea exchange rates is therefore critical.

\subsection{System overview}

A schematic of the gas exchange system is shown in Fig. 1. Its principal components are: (i) a sealed acrylic gas exchange tank that can be approximately half filled with seawater (Fig. 2 details its major features); (ii) an equilibration system used in preparing tank water subsamples for analysis; (iii) two gas chromatographs (GCs) identically configured for the analysis of $\mathrm{SF}_{6}, \mathrm{CH}_{4}$ and $\mathrm{N}_{2} \mathrm{O}$, in the tank headspace and in air that has been equilibrated with a tank water subsample. These components form a continuous, sealed circuit that can be decoupled and reconnected as required via the operation of solenoids. Details of the components are given in Sect. 3. The gas equilibration system is shown in Fig. 3 and the GC configuration in Fig. 4.

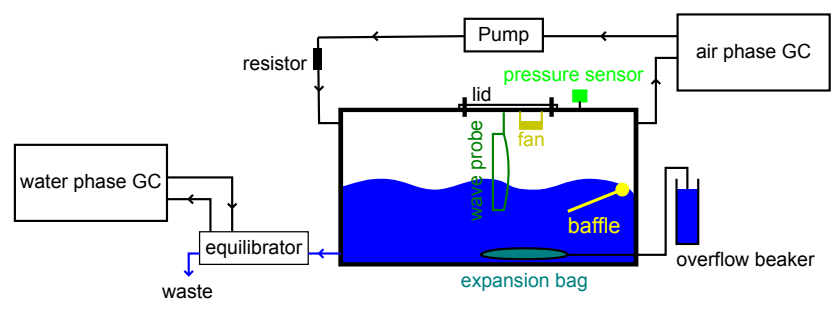

Figure 1. Schematic of the gas exchange experiment. The seawater sample $(93 \mathrm{~L})$ is contained in a gas-tight tank $(0.73 \mathrm{~m} \times 0.48 \mathrm{~m} \times$ $0.48 \mathrm{~m}$ internally). Water-side turbulence is created with a baffle driven by a stepper motor. An automatic equilibration circuit (details see Fig. 3) regularly takes water samples and equilibrates the water with an "equilibrator gas" of known $\mathrm{SF}_{6}, \mathrm{CH}_{4}$ and $\mathrm{N}_{2} \mathrm{O}$ composition, before measuring resulting gas partial pressures in a gas chromatograph (GC). Air phase gas partial pressures are constantly measured with a second GC. Wave spectra at a single point are acquired with a capacitance wave probe. Pressure and temperature in the tank and the equilibrator as well as total ambient pressure are continuously monitored.

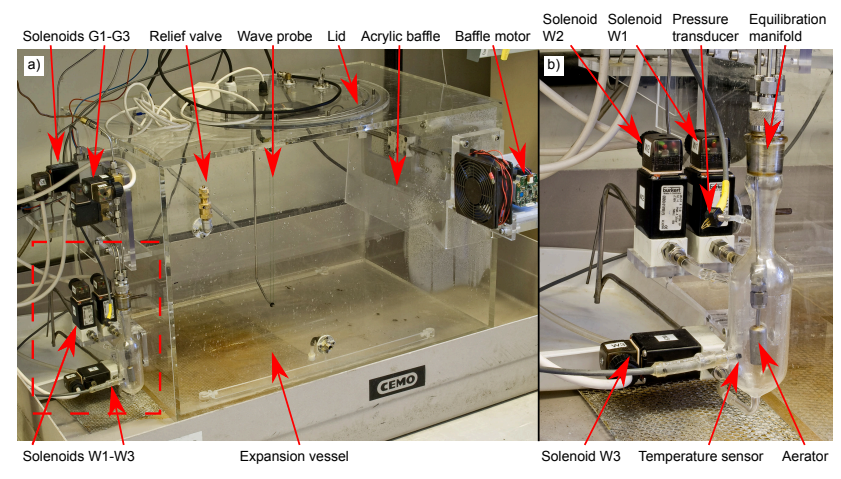

Figure 2. Annotated photograph of the gas exchange apparatus: (a) the gas exchange tank. Note that the overflow vessel usually connected to the expansion vessel is omitted for clarity; (b) the equilibration vessel shown by the dashed red box in image (a).

\section{System components}

\subsection{Gas exchange tank}

The basic structure of the gas exchange tank (Fig. 2) was custom-built (Bay Plastics Ltd, UK) for our $k_{\mathrm{w}}$-surfactant work. Subsequent modifications, principally the installation of mechanical and electronic components (see below), were carried out in-house. The tank has an internal base area of $0.73 \mathrm{~m} \times 0.48 \mathrm{~m}$, is $0.48 \mathrm{~m}$ in height internally and is constructed from $12 \mathrm{~mm}$ acrylic. Stainless steel bulkhead connectors are used for all tank connections. The incorporation of a headspace pressure relief valve precludes system overpressurisation and subsequent damage to the tank structure in the event of system malfunction. The tank is filled with sample gravimetrically to a notional volume of $(93.0 \pm 0.1) \mathrm{L}$, leaving a corresponding notional $74.1 \mathrm{~L}$ headspace $(1.11 \pm$ 
$0.01 \mathrm{~L}$ is accounted for by the baffle, expansion bag and holders). This method of filling was selected because it is important to reproduce the sample volume precisely. Small differences in the fill level can have a large effect on the degree of tank water turbulence, which is selected and controlled using an internal acrylic baffle mounted across the full width of the tank on a transverse shaft. The gravimetric procedure overcomes this problem. A stepper motor (PD2-116-60-SE: Trinamic, Germany) is located outside the tank and connected to the baffle shaft via a gas-tight bearing and Viton ${ }^{\circledR}$ seal. The motor is operated via a serial RS232 link and allows precise control of the forward and reverse motion of the baffle. The tank air-phase (headspace) is continuously mixed using a low throughput fan (Sanyo Denki 9S1212F4011: RS components, UK) that does not create any detectable water turbulence. The fan is mounted on the inside of a removable circular tank lid, along with a wave height gauge (Sect. 3.3). The lid facilitates access for maintenance, for internal tank cleaning and for filling with sample and is sealed using a double Viton ${ }^{\circledR}$ O-ring. Viton ${ }^{\circledR}$ is compatible with gaseous hydrocarbons and its use also precludes $\mathrm{SF}_{6}$ memory effects that may be encountered with some other seal materials (UpstillGoddard et al., 2003).

During operation (Sect. 4.2) aliquots of the tank water are automatically transferred to the equilibration vessel (Sect. 3.2). In order to prevent a progressive decrease in tank internal pressure due to this procedure, an expandable plastic bag (Supel Inert Film 10 L gas sampling bag, Sigma-Aldrich, UK) inside the tank is connected to a small external water reservoir containing artificial seawater (ASW) of salinity $\geq 45$ via a water-tight bulkhead fitting. The density contrast between the ASW and the tank seawater (maximum salinity $\approx 35$ ) ensures a negative buoyancy that prevents the expandable bag from rising from the bottom of the tank. A secondary, larger ASW reservoir is used to maintain the water level inside the small reservoir at the same level as in the exchange tank using a peristaltic pump; an overflow returns any excess back into the larger reservoir, thereby keeping the water level in the smaller reservoir constant.

Pressure in the tank headspace $\left(P_{\mathrm{h}}\right)$ is continuously monitored using a transducer (40PC001B: range $\pm 66.7 \mathrm{hPa}$; accuracy $0.5 \mathrm{hPa}$ : Honeywell, USA). The analogue output voltage is converted to a digital signal using a USB-6008 (12 bit) ADC (National Instruments, USA). Temperature in the tank water phase is recorded on an autonomous mini data logger (Minilog 8, Vemco, Canada; accuracy $0.2^{\circ} \mathrm{C}$ ) that is retrieved for data download at the end of each experiment.

\subsection{Equilibration vessel}

The analysis of dissolved gases by gas chromatography necessitates either a pre-extraction or equilibration step, followed by the measurement of gas partial pressures in the resulting gas phase and corrections for air and water volumes and gas solubilities (Upstill-Goddard et al., 1996). Extraction

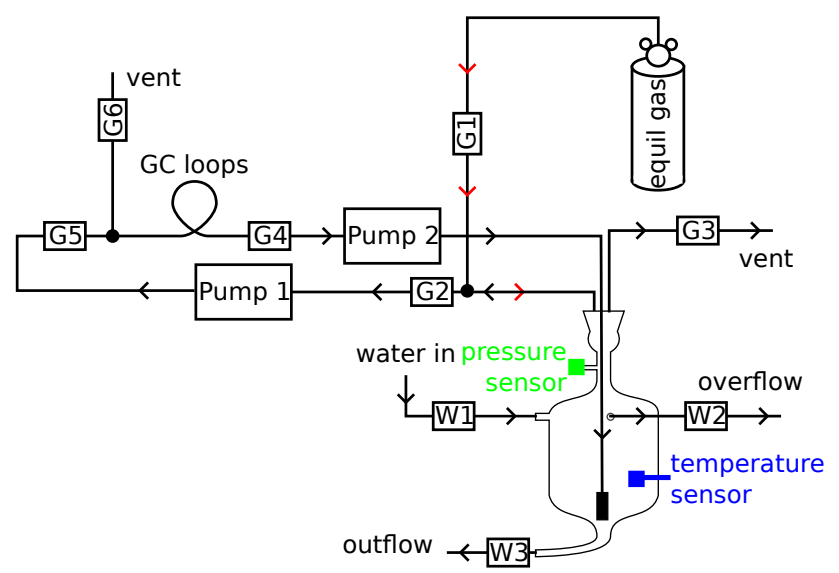

Figure 3. Schematic of the equilibration system. For circuit operation see text.

techniques often involve pre-concentration procedures which can be complicated and the overall extraction efficiency can vary significantly. By contrast, automated gas equilibration has been shown to be highly reproducible (Upstill-Goddard et al., 1996). We therefore incorporated a water-air equilibration vessel as an integral component of the gas exchange tank apparatus. The equilibration vessel has a total internal volume of $183 \mathrm{~cm}^{3}$ and has two principal components: a glass vessel equilibrator and a removable stainless steel equilibration manifold (Fig. 3). The design derives from a system we constructed for the high-precision analysis of dissolved gases at sea (Upstill-Goddard et al., 1996). The equilibration manifold comprises three lengths of stainless steel tubing silversoldered through a tapered stainless steel plug machined to seat precisely in the neck of the glass vessel to give a gastight seal. Two tubes are cut flush to the base of the plug and a third is connected to a stainless steel aerator frit near the bottom of the glass vessel. The frit is a standard chromatography solvent filter (Thames Restek, UK). The equilibration vessel has three water inlet/outlets (all $4 \mathrm{~mm}$ i.d.), each connected via a short length of flexible Tygon ${ }^{\circledR}$ tubing to a solenoid (Burkert 0124 2/2 way for aggressive media, Burkert, Germany; W1-W3 in Fig. 3). A digital temperature sensor (DS18B20+; resolution $0.1^{\circ}$; accuracy $<0.5^{\circ}$ : Maxim, USA) is housed in a side arm. A second side arm in the equilibrator neck houses a pressure transducer identical to that used for monitoring tank headspace pressures (Sect. 3.1). A cylinder containing compressed air of known $\mathrm{SF}_{6}, \mathrm{~N}_{2} \mathrm{O}$ and $\mathrm{CH}_{4}$ composition (the "equilibrator gas") is connected via solenoid G1. The gas is circulated through G2, the GC sample loops and back through the equilibrator frit. Solenoid G3 allows venting of the equilibrator during its filling with seawater via W1. Solenoids G1-G3 are Burkert 6013A 2/2 way (Burkert, Germany).

Prior to equilibration the equilibration vessel and all associated GC sample tubing is flushed with the equilibrator gas via solenoid G1. Next the vessel is completely filled 


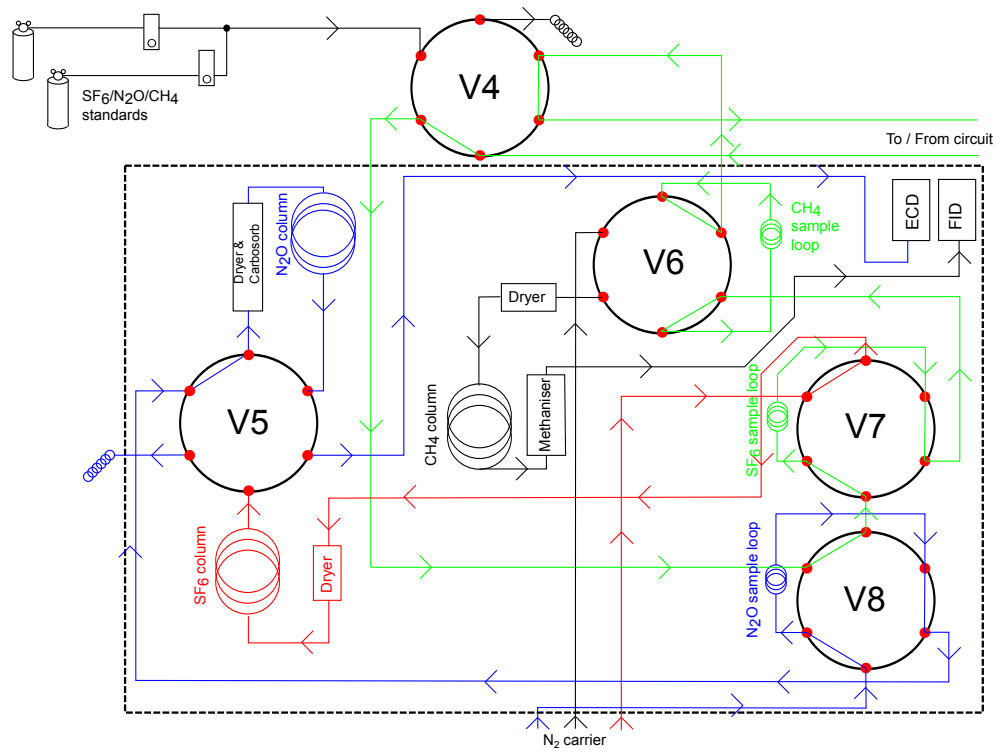

Figure 4. Schematic of the GC system used to measure $\mathrm{SF}_{6}, \mathrm{~N}_{2} \mathrm{O}$, and $\mathrm{CH}_{4}$, here in $\mathrm{N}_{2} \mathrm{O}$ inject mode. Each sample loop can be injected separately using the corresponding valve (V3, V4, and V5, respectively). For the ECD, the $\mathrm{N}_{2} \mathrm{O}$ and the $\mathrm{SF}_{6}$ column can be selected with valve V2. For detailed description see text.

with tank water via solenoid W1, all air being displaced via solenoid G3. A headspace of equilibrator gas is then introduced via G1, displacing sample via the overflow and solenoid W2. The fill/displacement cycle is then repeated to ensure the removal of all traces of previous sample and equilibrator gas. The procedure facilitates a reproducible headspace to water volume ratio (Sect. 4.4.2) which is required for accurately correcting for solubility-driven phase partitioning during equilibration (Upstill-Goddard et al., 1996). All solenoids are then closed and G2, G4 and G5 are opened. Two gas sampling pumps (NMP015.1.2KNL: KNF Neuberger AG, Switzerland) circulate the equilibrated sample gas around the closed circuit, through the GC sample loops and back through the equilibrating water sample via the aerator frit inside the equilibrator for $4.35 \mathrm{~min}$. Equilibrationtime curves (Fig. 5) show that all three gases are fully equilibrated within $3 \mathrm{~min}$. Two pumps are necessary to equalise pressure gradients and thus maintain the internal equilibrator pressure at ambient. Pumping rates are regulated via 8 bit pulse width modulation of the $12 \mathrm{~V}$ supply. The speed of pump 1 is kept constant and that of pump 2 is regulated in response to the equilibrator internal pressure.

Following equilibration the pumps are switched off, all solenoids are closed and G6 is opened for $20 \mathrm{~s}$ to allow the GC sample loops to reach ambient atmospheric pressure before injection onto the GC carrier gas lines. This avoids pressure effects that might otherwise interfere with the detector responses.

Each equilibration step removes $549 \mathrm{~mL}$ of water from the gas exchange tank. This is around $0.59 \%$ of the initial tank water volume and the total cumulative volume removed during a typical experiment is therefore less than $4 \%$ of the initial volume. This is accounted for in subsequent data processing, the required corrections being smaller than for our experiments with an earlier gas exchange tank (UpstillGoddard et al., 2003).

\section{Determining equilibration volumes}

The relative volumes of water to headspace $V_{\mathrm{a}} / V_{\mathrm{w}}$ involved in the equilibration step must be accurately known in order to facilitate corrections for solubility-driven phase partitioning (Upstill-Goddard et al., 1996). $V_{\mathrm{w}}$ can be determined gravimetrically by repeatedly generating headspace in the equilibrator. By contrast, system configuration precludes directly measuring $V_{\mathrm{a}}$. To overcome this we directly estimated $V_{\mathrm{a}} / V_{\mathrm{w}}$ by equilibration, similar to Upstill-Goddard et al. (1996). The gas exchange tank was filled with $93 \mathrm{~L}$ Milli-Q water (resistivity typically $18.2 \mathrm{M} \Omega \mathrm{cm}^{-3}$ : Millipore Corporation, USA) enriched with $\mathrm{SF}_{6}, \mathrm{~N}_{2} \mathrm{O}$ and $\mathrm{CH}_{4}$, sealed and equilibrated by operating the baffle until the gas partial pressures in both the equilibrator headspace and in the tank headspace remained constant for $>12 \mathrm{~h}$. For this measurement ultrahigh purity (UHP) $\mathrm{N}_{2}\left(>99.999 \% \mathrm{~N}_{2}\right.$, no detectable $\mathrm{SF}_{6}$, $\mathrm{N}_{2} \mathrm{O}$ or $\mathrm{CH}_{4}$ ) was used as equilibrator gas, i.e. $C_{0}=0$. Concentrations in the tank headspace and equilibrator were then determined multiple times and averaged. These values were used together with the appropriate Ostwald solubilities of $\mathrm{SF}_{6}$ (Bullister et al., 2002), $\mathrm{CH}_{4}$ (Wiesenburg and Guinasso, 1979) and $\mathrm{N}_{2} \mathrm{O}$ (Weiss and Price, 1980) at the temperature and pressure of equilibration and the tank headspace and 


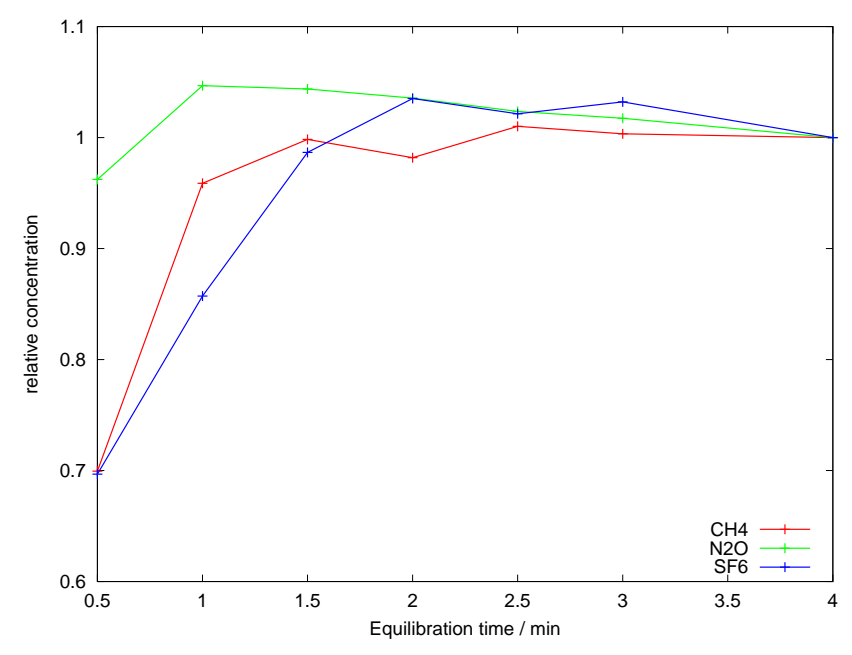

Figure 5. Relative gas concentration vs. equilibration time for $\mathrm{SF}_{6}$, $\mathrm{N}_{2} \mathrm{O}$ and $\mathrm{CH}_{4}$.

water volumes, to calculate $V_{\mathrm{a}} / V_{\mathrm{w}}$ according to Eq. (17). For the system as currently configured $V_{\mathrm{a}} / V_{\mathrm{w}}=0.79 \pm 0.02$.

\subsection{Wave height gauge}

A capacitance-type high-precision wave height gauge (AWP24; $30 \mathrm{~cm}$ double strand sensing wire, Akamina Technologies, Canada) is used. Analogue output voltage is digitised at $400 \mathrm{~Hz}$ (USB-6008 ADC, National Instruments, USA). The output voltage of the device is linearly proportional to the water level.

The probe is routinely calibrated to determine the relationship between water depth and output voltage by filling the gas exchange tank with sample water and progressively immersing the probe step-wise into the water. This is done by mounting the probe on a rod with precisely machined holes at $1 \mathrm{~cm}$ intervals. For each step the rod is bolted through one of the holes to a sturdy mount secured to the tank. After waiting for the water surface to settle, the output voltage is averaged over $10 \mathrm{~s}$. A line is fitted to the immersion depth-voltage relation.

\subsection{Ancillary measurements}

Absolute pressure $\left(P_{0}\right)$ and temperature $(T)$ in the laboratory are measured using a digital sensor (Sensortec BMP085; pressure range $300-1100 \mathrm{hPa}$; absolute pressure accuracy $1 \mathrm{hPa}$; absolute temperature accuracy $0.5^{\circ} \mathrm{C}$ : Bosch, Germany).

\subsection{Gas chromatography}

The need to determine the partial pressures of $\mathrm{SF}_{6}, \mathrm{CH}_{4}$ and $\mathrm{N}_{2} \mathrm{O}$ in both the air and water phases during an experiment precludes using a single GC; this would necessitate long sampling intervals and/or a long experimental duration, with consequent loss of experimental resolution. Therefore, two identically configured GCs were used (both HP 5890), one for analysing tank headspace ("air-phase GC") and one for analysing equilibrator air following water sample equilibration ("water-phase GC"). The analysis is identical in each $\mathrm{GC}$, being isothermal $\left(60^{\circ} \mathrm{C}\right)$ and based on methods developed in our laboratory (Upstill-Goddard et al., 1990, 1996, 2003). A schematic is shown in Fig. 4. A series of motor-driven stainless steel chromatography valves, V1-V5 in Fig. 4 (Valco: Vici AG, Switzerland), allow the selective switching of tank headspace, equilibrator headspace and calibration standards onto the separating columns (one each for $\mathrm{SF}_{6}, \mathrm{~N}_{2} \mathrm{O}$ and $\mathrm{CH}_{4}$ in each GC) and detectors, via fixed volume sample loops (internal volume: $\mathrm{SF}_{6} 10 \mathrm{~mL}, \mathrm{CH}_{4} 1 \mathrm{~mL}$, $\mathrm{N}_{2} \mathrm{O} 1.5 \mathrm{~mL}$ ). Chromatographic separation of $\mathrm{SF}_{6}$ is on Molecular Sieve $5 \mathrm{~A}$ columns $(4 \mathrm{~m} \times 1.75 \mathrm{~mm}$ i. d. $)$, whereas $\mathrm{N}_{2} \mathrm{O}$ and $\mathrm{CH}_{4}$ are both separated on 80-100 mesh Porapak Q columns $\left(\mathrm{CH}_{4}, 4 \mathrm{~m} \times 1.75 \mathrm{~mm}\right.$ i. d.; $\mathrm{N}_{2} \mathrm{O}, 5 \mathrm{~m} \times 1.75 \mathrm{~mm}$ i. d.). The GC carrier gas is UHP $\mathrm{N}_{2}$. Flow rates are typically around $25 \mathrm{~cm}^{3} \mathrm{~min}^{-1}$ for $\mathrm{CH}_{4}$ and $\mathrm{N}_{2} \mathrm{O}$, and $50 \mathrm{~cm}^{3} \mathrm{~min}^{-1}$ for $\mathrm{SF}_{6}$. Water vapour produced during sample equilibration is removed using $\mathrm{Mg}(\mathrm{ClO} 4) 2$ and $\mathrm{CO}_{2}$ is removed using $\mathrm{NaOH}$ (Upstill-Goddard et al., 1996). Detection of $\mathrm{CH}_{4}$ uses a flame ionisation detector (FID) at $300^{\circ} \mathrm{C}$ whereas detection of $\mathrm{N}_{2} \mathrm{O}$ and $\mathrm{SF}_{6}$ uses an Electron Capture Detector (ECD) with a ${ }^{63} \mathrm{Ni}$ source at $350{ }^{\circ} \mathrm{C}$.

The GC responses are integrated automatically using proprietary GC software (Clarity: DataApex, Prague, Czech Republic). Method calibration uses a series of mixed calibration standards prepared by pressure dilution in UHP $\mathrm{N}_{2}$ (UpstillGoddard et al., 1990, 1996). Analytical precisions are typically $\pm 1 \% \mathrm{CH}_{4}, \pm 0.8 \% \mathrm{~N}_{2} \mathrm{O}$ and $\pm 1 \% \mathrm{SF}_{6}$. All three gases are analysed in less than $8 \mathrm{~min}$.

\subsection{Limits of detection}

Minimum detectable levels of $\mathrm{SF}_{6}, \mathrm{~N}_{2} \mathrm{O}$ and $\mathrm{CH}_{4}$ have been determined by estimating the detector responses corresponding to a signal-to-baseline-noise ratio of 2 and dividing by the detector peak width (peak area/peak height) in seconds (Upstill-Goddard et al., 1996). Minimum detectable levels are 0.5 pptv $\mathrm{SF}_{6}, 0.2$ ppbv $\mathrm{N}_{2} \mathrm{O}$ and 10 ppbv $\mathrm{CH}_{4}$. However, in practice the partial pressures of all three gases in the equilibrator gas combined with solubility considerations (Bullister et al., 2002; Wiesenburg and Guinasso, 1979; Weiss and Price, 1980) preclude operating the detectors close to these limits.

\section{Experimental procedure}

Prior to use, all ancillary equipment is thoroughly cleaned with ethanol and rinsed with Milli-Q water. All metal and glassware is subsequently baked at $450^{\circ} \mathrm{C}$ overnight. 


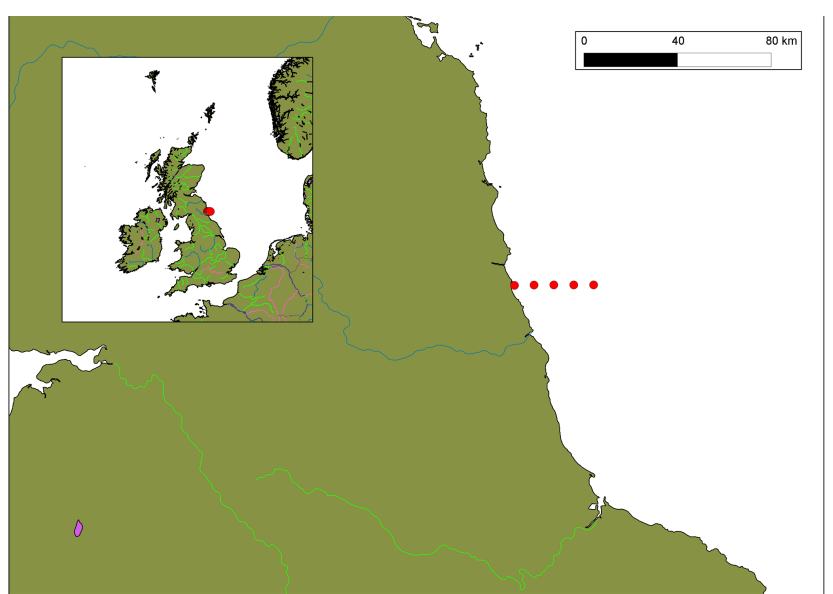

Figure 6. The sampling stations (red circles) on the transects in the coastal North Sea off northeast England.

\subsection{Field sampling}

Large-volume water samples $(\approx 100 \mathrm{~L})$ for the gas exchange experiments were collected during two coastal North Sea transects of R/V Princess Royal, on 4 October 2012 and 13 February 2013. On both, samples were collected from five fixed locations approximately equally spaced up to $20 \mathrm{~km}$ off-shore of the UK Northumberland coast (Fig. 6). The samples were drawn with an on-board sampling pump and stored on-deck in "aged" polyethylene seawater carboys (i.e. all leachable components removed using concentrated $\mathrm{HCl}$ solution). Additional samples for the measurement of surfactant activity were collected from the surface microlayer (SML) using a Garrett (1965) screen (for further details of our Garrett screen samplers, see Schneider-Zapp et al., 2013) and decanted into sterile polypropylene sampling tubes; for samples from the underlying water (ULW), water was drawn using a stainless steel bucket, then sterile polypropylene tubes were opened below the water surface of the bucket, filled, and closed using nitrile gloves to avoid sampling SML. All these samples were kept refrigerated in the dark at $4{ }^{\circ} \mathrm{C}$ to minimise degradation during pre-analysis storage (SchneiderZapp et al., 2013). Salinity and temperature were measured using a hand-held probe. Meteorological data were acquired via an on-board weather station.

\subsection{Gas exchange experiments}

The inside of the gas exchange tank is repeatedly cleaned and filled/rinsed with Milli-Q water until surfactant activity (SA) in the tank water surface microlayer (SML) is analytically identical to that of fresh Milli-Q (within between 0.02 eq. $\mathrm{mg} \mathrm{L}^{-1} \mathrm{~T}-\mathrm{X}-100$ and max. 0.04 eq. $\mathrm{mg} \mathrm{L}^{-1} \mathrm{~T}-\mathrm{X}$ 100). The SML is routinely collected with a small Garrett (1965) screen and SA is measured by hanging mercury drop AC voltammetry (see Sect. 4.3).
Following cleaning and thorough rinsing of the inside of the tank with sample, the tank is filled with $93 \mathrm{~L}$ of sample (measured gravimetrically), which is added directly from sampling carboys using a peristaltic pump. During this procedure $1.1 \mathrm{~L}$ of sample is decanted directly from one of the carboys into a sealable glass bottle and enriched with $\mathrm{SF}_{6}$, $\mathrm{N}_{2} \mathrm{O}$ and $\mathrm{CH}_{4}$ as follows: $80 \mathrm{~cm}^{3}$ of 10 ppmv $\mathrm{SF}_{6}$ in UHP $\mathrm{N}_{2}$, prepared by pressure dilution (Upstill-Goddard et al., 1990, 1996), $20 \mathrm{~cm}^{3}$ of $\geq 99.99 \%$ research grade $\mathrm{CH}_{4}$ and $1 \mathrm{~cm}^{3}$ of $99.998 \%$ research grade $\mathrm{N}_{2} \mathrm{O}$ are injected into the vessel and equilibrated with the sample water for 20 min using a small pump and aerator. This gas-enriched subsample is added to the tank at the end of the filling procedure to give the final, notional $93 \mathrm{~L}$ volume and the tank is then sealed.

To estimate the sample volume, the carboys (including that of the gas enriched subsample) are weighed before and after filling. The weight difference quantifies the sample mass, which is converted to volume using sample density derived from its salinity and temperature. These are measured in the residual sample in the carboys directly after filling, using a pre-calibrated hand-held probe, in order to preclude any possible contamination of the tank water sample. Continuous weighing during the filling process allows the filling procedure to be terminated when the correct nominal volume is reached.

The enriched subsample creates a disequilibrium in gas partial pressures between the tank water and tank headspace, so as to drive measurable water-to-air exchange of the measured gases during the experiment. Note that for a subset of our tests, the $\mathrm{N}_{2} \mathrm{O}$ chromatography was not yet fully operational. To be consistent, we decided to only show data for $\mathrm{CH}_{4}$ and $\mathrm{SF}_{6}$, where measurements are available for all data sets.

A configuration file defining all experimental settings is read by the control program which executes the experiment. The system is optimised to run a gas exchange experiment in just under $3.25 \mathrm{~h}$. We routinely use three sequential fixed levels of turbulence, each of 64.5 min duration; corresponding baffle frequencies are $0.6,0.7$, and $0.75 \mathrm{~Hz}$. GC analysis of the tank headspace and equilibrated water phases is every 10.75 min, enabling six measurements of each phase for each selected level of turbulence during an experiment. Temperatures and pressures are logged every $0.1 \mathrm{~min}$. Immediately prior to and following each experiment, calibration gas standards are repeatedly measured on each GC for data calibration and to allow an estimate of detector drift. This is usually less than $2 \%$ over the course of a typical experiment and is corrected for by applying a time-dependent linear fit to the detector responses.

Gas concentration uncertainties are estimated using the standard deviation of the standard measurements. For all other measured quantities, specified instrument accuracies are used. In the calculations, Gaussian error propagation (Tayler, 1996, chapter 3; for details of the calculations see the Appendix) is used to propagate uncertainties. This 
over-estimates the uncertainty, because not all uncertainties are independent, but covariance matrices are not known. For example, the GC errors include the detector drift of up to $2 \%$ as estimated from the standard measurements. This effect cannot be separated from the statistical error or corrected for, as the drift is irregular.

Estimates of $k_{\mathrm{w}}$ are obtained from Eq. (13) using weighted linear regression (Sect. 4.4.1). The uncertainty is estimated from the weighted fit. Convention is to scale all measured values of $k_{\mathrm{w}}$ to Schmidt numbers of either 660 or 600 , being the values for $\mathrm{CO}_{2}$ in freshwater and salinity 35 seawater respectively, at $20^{\circ} \mathrm{C}$. Therefore, $k_{\mathrm{w}}$ estimates are scaled to Schmidt number 660 using Eq. (19) (Sect. 4.4.3). Schmidt numbers are obtained from Wanninkhof (1992). From the Milli-Q data, a Schmidt number exponent of $n=1 / 2$ was determined using Eq. (20), corresponding to a wavy surface.

The wave frequency energy spectrum (Phillips, 1980) is calculated from the sampled wave height using the method of Welch (1967) (see Harris, 1978, for more information) with a Hann window of length 131072 . For the measurement frequency of $400 \mathrm{~Hz}$, used here, the Nyquist frequency is $200 \mathrm{~Hz} \approx 1257 \mathrm{rad} \mathrm{s}^{-1}$; however, noise begins to affect the measurements at frequencies lower than this. We plotted the results up to $500 \mathrm{rad} \mathrm{s}^{-1} \approx 80 \mathrm{~Hz}$, since we consider these data to be unaffected by noise.

\subsection{Surfactant measurement}

Surfactant activity (SA) is measured using AC voltammetry (Ćosović and Vojvodić, 1982) (Metrohm 797 VA Computrace, Metrohm, Switzerland) with a hanging mercury drop, a silver/silver chloride reference electrode and a platinum wire auxiliary electrode. Samples are brought to salinity 35 prior to measurement by adding surfactant-free $\mathrm{NaCl}$ solution. For each measurement, a new mercury drop is created and the first few drops discarded. Surfactants accumulate on the drop at $V=-0.6 \mathrm{~V}$ for 15 or $60 \mathrm{~s}$ with stirring (1000 rpm). Alternating voltage scans of $10 \mathrm{mV}$ at $75 \mathrm{~Hz}$ produce a current which is measured. Instrument calibration uses the non-ionic soluble surfactant Triton T-X-100. Each response is corrected for the added $\mathrm{NaCl}$ solution and expressed as an equivalent $\mathrm{T}-\mathrm{X}-100$ concentration.

\subsection{Theory}

\subsubsection{Tank gas exchange}

For a sealed gas exchange tank containing seawater and air and without gas sources or sinks, Eq. (1) can be used to derive a mass balance:

$$
\left(\begin{array}{l}
\frac{\partial C_{\mathrm{a}}}{\partial t} V_{\mathrm{a}} \\
\frac{\partial C_{\mathrm{w}}}{\partial t} V_{\mathrm{w}}
\end{array}\right)=k_{\mathrm{w}}\left(\begin{array}{c}
C_{\mathrm{w}}-\alpha C_{\mathrm{a}} \\
\alpha C_{\mathrm{a}}-C_{\mathrm{w}}
\end{array}\right) A .
$$

The solubility $\alpha$, volumes $V_{\mathrm{a}}$ and $V_{\mathrm{w}}$, and surface area $A$ are assumed to be constant. In reality, $\alpha$ depends on temperature. In practice changes in experimental temperature are of the order of $0.5^{\circ} \mathrm{C}$. For such a change in temperature at $20^{\circ} \mathrm{C}$, the change in $\alpha$ is $<1.6 \%$ for $\mathrm{SF}_{6},<1.4 \%$ for $\mathrm{N}_{2} \mathrm{O}$ and $<1 \%$ for $\mathrm{CH}_{4}$ according to published parameterisations (Bullister et al., 2002; Wiesenburg and Guinasso, 1979; Weiss and Price, 1980).

Let the height of phase $i$ (i.e. air a or water w) be $h_{i}$, i.e. $h_{i}:=V_{i} / A$, and let

$D:=C_{\mathrm{w}}-\alpha C_{\mathrm{a}}$.

Re-arranging Eq. (3), taking the derivative and using the chain rule results in

$$
\frac{\partial C_{\mathrm{a}}}{\partial t}=\frac{1}{\alpha}\left[\frac{\partial C_{\mathrm{w}}}{\partial t}-\frac{\partial D}{\partial t}\right]=\frac{k_{\mathrm{w}}}{h_{\mathrm{a}}} D
$$

where Eq. (2) (top) has been used in the last equality. Substituting $\frac{\partial C_{\mathrm{w}}}{\partial t}$ into Eq. (2) (bottom), a differential equation in $D$ is obtained:

$$
\frac{\partial D}{\partial t}+k_{\mathrm{w}} \underbrace{\left[\frac{1}{h_{\mathrm{w}}}+\frac{\alpha}{h_{\mathrm{a}}}\right]}_{=: \beta}=0 .
$$

Solving this gives

$$
D=D_{0} \exp \left(-k_{\mathrm{w}} \beta t\right),
$$

where $D_{0}:=D(t=0)$.

Due to conservation of mass, the total amount of gas $N$ in the system must remain constant. Hence,

$N=C_{\mathrm{a}} V_{\mathrm{a}}+C_{\mathrm{w}} V_{\mathrm{w}}=$ const.

This relation serves as a routine check of the experimental results and system integrity; a change in the value of $N$ during the experiment implies system leaks and/or defective chromatography.

At each equilibration step the tank water volume $V_{\mathrm{w}}$ decreases (here assumed instantaneously) by volume $V_{\mathrm{s}}$, such that $V_{\mathrm{w}>}=V_{\mathrm{w}<}-V_{\mathrm{s}}$, where $V_{\mathrm{w}<}$ and $V_{\mathrm{w}>}$ are the tank water volumes before and after drawing the sample, respectively. The effect is to change the value of $\beta$ so that the differential equation no longer has constant coefficients. However, within each interval $\left[t_{n}, t_{n+1}\right]$ between two measurements at times $t_{n}$ and $t_{n+1}$, the volumes are constant and Eq. (6) can be used. At each sampling step the values of the coefficients change instantaneously; the variables at the end of the previous interval become the initial conditions for the next interval. If $V_{\mathrm{e}, n}=n V_{\mathrm{s}}$ is the total water volume already extracted at $t_{n}$, using the abbreviations $V_{\mathrm{w}, n}:=\left.V_{\mathrm{w}}\right|_{t=t_{n}}, D_{n}:=D(t=$ $\left.t_{n}\right)$ and

$$
\begin{aligned}
\beta_{n} & :=\left.\beta\right|_{t=t_{n}}=\frac{A}{V_{\mathrm{w}, n-1}-V_{\mathrm{s}}}+\frac{A \alpha}{V_{\mathrm{a}}} \\
& =\frac{A}{V_{\mathrm{w}, 0}-n V_{\mathrm{s}}}+\frac{A \alpha}{V_{\mathrm{a}}}=\frac{1}{h_{\mathrm{w}, 0}-n h_{\mathrm{s}}}+\frac{\alpha}{h_{\mathrm{a}}}
\end{aligned}
$$


derives

$D_{n}=D_{n-1} \exp \left(-k_{\mathrm{w}} \beta_{n}\left(t_{n}-t_{n-1}\right)\right)$

The first water sample is drawn at $t_{0}$, the experiment starts running with the reduced water volume $V_{\mathrm{w}}-V_{\mathrm{s}}$ and thus the system response is

$D_{n}=D_{0} \exp \left(-k_{\mathrm{w}} \sum_{j=1}^{n} \beta_{j}\left(t_{j}-t_{j-1}\right)\right)$.

Note that for $n=0$, the sum is zero and the equation is identical to the original Eq. (6). The new solution Eq. (10) is not in the form exp $-k_{\mathrm{w}} \beta t$ but has a sum of different $t_{j}$ in its exponential. It can be solved for $k_{\mathrm{w}}$; however, it diverges for $n=0$. This is overcome by conversion to the form $\exp -k_{\mathrm{w}} \beta t$ as

$D_{n}=D_{0} \exp \left(-k_{\mathrm{w}}^{\left[\sum_{j=1}^{n} \beta_{j} \frac{t_{j}-t_{j-1}}{t_{n}-t_{0}}\right]}(\underbrace{}_{=: B_{n}}\left(t_{n}-t_{0}\right))\right.$

with

$$
\begin{aligned}
B_{n}: & =\sum_{j=1}^{n} \beta_{j} \frac{t_{j}-t_{j-1}}{t_{n}-t_{0}} \\
& =\frac{A}{t_{n}-t_{0}} \sum_{j=1}^{n} \frac{t_{j}-t_{j-1}}{V_{\mathrm{w}, 0}-j V_{\mathrm{s}}}+\frac{A \alpha}{V_{\mathrm{a}}} .
\end{aligned}
$$

Note that $B_{0}=\beta_{0}$ (Eqs. 11 and 6 ). For $V_{\mathrm{s}}=0$, we obtain $B_{n}=\beta_{0}$ and the solution reduces to Eq. (6) with $t_{0}=0$. With $V_{\mathrm{s}}>0$, the value of $B_{n}$ increases (the denominator in each summand is decreased) and consequently $D$ decreases progressively more rapidly with increasing experimental run time during which further water is extracted from the tank. Consequently, some fraction of the decrease in $D$ is due to volume extraction. Without any correction for this, $k_{\mathrm{W}}$ is overestimated. The factor $\frac{t_{j}-t_{j-1}}{t_{n}-t_{0}}$ is applied as a weight factor for any given water volume during the experiment.

The solution can be expressed in logarithmic form to derive a linear fit obtaining $k_{\mathrm{W}}$ as

$\chi_{n}:=\frac{1}{B_{n}} \ln \frac{D_{0}}{D_{n}}=k_{\mathrm{w}}\left(t_{n}-t_{0}\right)$.

The mass balance Eq. (7) also has to be adjusted to account for the water loss on sampling:

$N_{n}=V_{\mathrm{w}, n} C_{\mathrm{w}, n}+\sum_{j=1}^{n} C_{\mathrm{w}, j-1} V_{\mathrm{s}}+V_{\mathrm{a}} C_{\mathrm{a}, n}$

\subsubsection{Water sample equilibration}

We can consider a water sample of volume $V_{\mathrm{w}}$ in the equilibrator with an initial dissolved gas concentration $C_{\mathrm{w}}$ at in situ pressure $P_{1}$ and temperature $T_{1}$. The number of moles of gas in the water is $N_{1}=C_{\mathrm{w}} V_{\mathrm{w}}$.

The water subsample then equilibrates with a head space of volume $V_{\mathrm{a}}$ and initial gas concentration $C_{0}$. The total number of moles of gas in the equilibrator is then $N=N_{1}+N_{0}=$ $V_{\mathrm{w}} C_{\mathrm{w}}+V_{\mathrm{a}} C_{0}$. During equilibration the gas partitions according to $\alpha C_{\mathrm{a}}^{\prime}=C_{\mathrm{w}}^{\prime}$, where $\alpha$ is the Ostwald solubility coefficient. $N$ remains constant (conservation of mass), thus

$V_{\mathrm{a}} C_{\mathrm{a}}^{\prime}+V_{\mathrm{w}} C_{\mathrm{w}}^{\prime}=V_{\mathrm{a}} C_{\mathrm{a}}^{\prime}+V_{\mathrm{w}} \alpha C_{\mathrm{a}}^{\prime}=V_{\mathrm{a}} C_{0}+V_{\mathrm{w}} C_{\mathrm{w}} \cdot$

Solving for $C_{\mathrm{w}}$ results in

$C_{\mathrm{w}}=\frac{V_{\mathrm{a}}}{V_{\mathrm{w}}}\left(C_{\mathrm{a}}^{\prime}-C_{0}\right)+\alpha C_{\mathrm{a}}^{\prime}$,

which can be used to back-calculate the gas concentration in the water sample using $C_{\mathrm{a}}^{\prime}$.

For evaluating Eq. (16), the water-headspace volume ratio $V_{\mathrm{a}} / V_{\mathrm{w}}$ is required. It is determined by a measurement with known $C_{\mathrm{w}}$ and $C_{\mathrm{a}}^{\prime}$ so that Eq. (15) is then solved for $V_{\mathrm{a}} / V_{\mathrm{w}}$ :

$\frac{V_{\mathrm{a}}}{V_{\mathrm{w}}}=\frac{C_{\mathrm{w}}-\alpha C_{\mathrm{a}}^{\prime}}{C_{\mathrm{a}}^{\prime}-C_{0}}$.

\subsubsection{Schmidt number scaling}

The value of $k_{\mathrm{w}}$ for any gas is a function of its Schmidt number $S c$, which is defined as the ratio of the viscosity of water to the corresponding gas diffusivity at the requisite temperature, i.e. $S c=v / D$. Theory predicts the scaling

$k_{\mathrm{w}}=\frac{u_{*}}{R} S c^{-n}$

where $u_{*}$ is the friction velocity, $R$ is the resistance for momentum transfer and the exponent $n$ is equal to $2 / 3$ for a smooth surface and $1 / 2$ for a rough surface with a smooth transition (Richter and Jähne, 2010). This relation allows the interconversion of $k_{\mathrm{w}}$ for any given gas to $k_{\mathrm{w}}$ for any other specified gas. Given two gases 1 and 2 with transfer velocities $k_{\mathrm{w} 1}$ and $k_{\mathrm{w} 2}$ and $S c h m i d t$ numbers $S c_{1}$ and $S c_{2}$, respectively, one obtains

$k_{\mathrm{w} 1}=\left(\frac{S c_{1}}{S c_{2}}\right)^{-n} k_{\mathrm{w} 2}$.

Simultaneous measurements of two gases with different Schmidt numbers can be used to calculate the exponent:

$n=\frac{\ln \frac{k_{\mathrm{w} 1}}{k_{\mathrm{w} 2}}}{\ln \frac{S c_{2}}{S c_{1}}}=\frac{\ln \frac{k_{\mathrm{w} 1}}{k_{\mathrm{w} 2}}}{\ln \frac{D_{1}}{D_{2}}}$. 


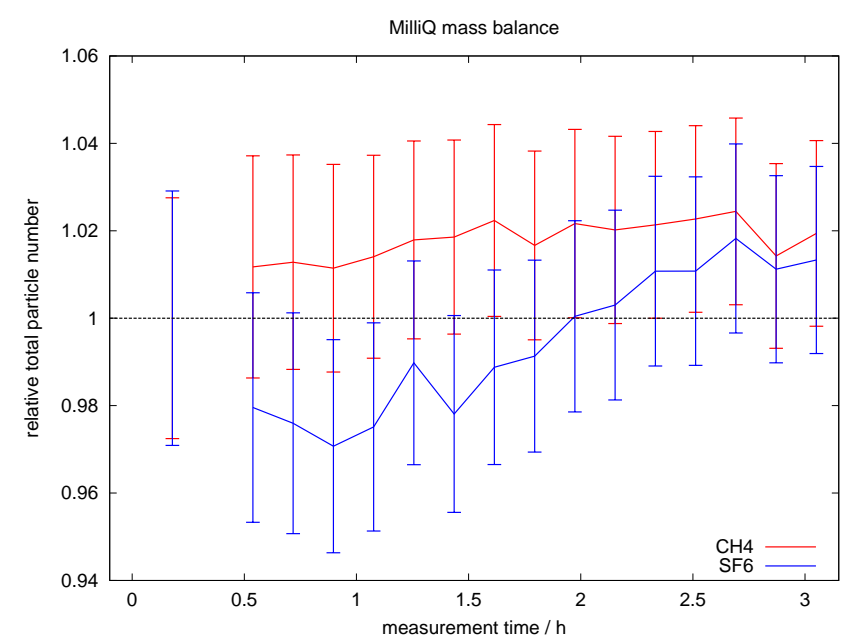

Figure 7. Total amount of gas in the tank according to Eq. (14), normalised to the first measurement, vs. time of a typical gas exchange experiment with Milli-Q water. It shows that no gas is measurably lost or acquired during the experiment.

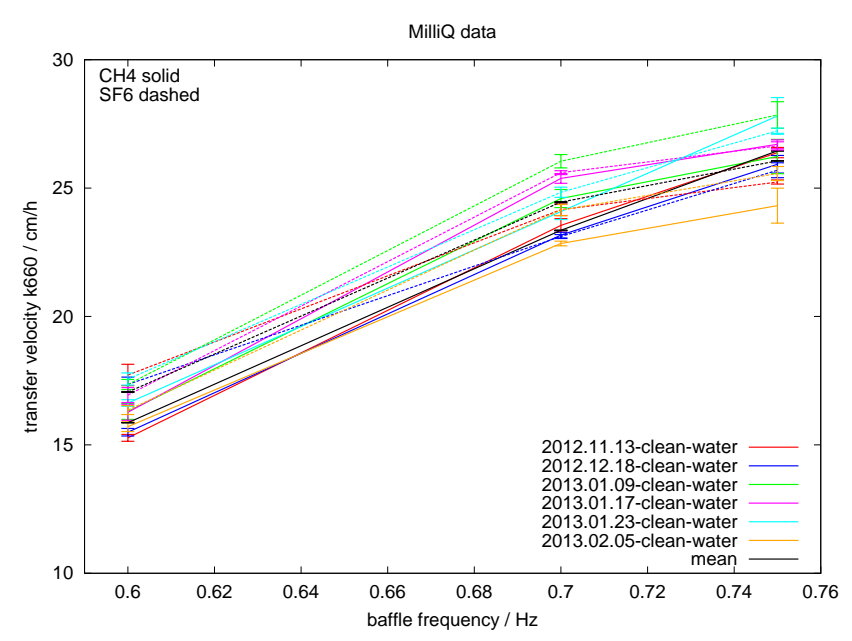

Figure 8. Estimated transfer velocities of Milli-Q water scaled to Schmidt number 660 at three different baffle settings for 6 different experiments, for both $\mathrm{CH}_{4}$ and $\mathrm{SF}_{6}$.

\section{Results and discussion}

\subsection{Evaluation procedure}

To test the evaluation procedure, synthetic data were used. After choosing a nominal value of $k_{\mathrm{w}}$, an initial condition $C_{\mathrm{w}, 0}, C_{\mathrm{a}, 0}$, and constants $T$ and $S$, the true system response was calculated using Eq. (10), with volumes and dimensions from the experimental setup. Gaussian noise with mean 0 and variance of $2 \%$ was added to the true gas concentrations to model the measurement process. The data were then put into the evaluation procedure. The original transfer velocity $k_{\mathrm{w}}$ was always within the uncertainty of the estimated transfer velocity.
Table 1. Estimated values of $k_{660}$ derived from $\mathrm{CH}_{4}$ and $\mathrm{SF}_{6}$ for six different Milli-Q experiments.

\begin{tabular}{lcc}
\hline & \multicolumn{2}{c}{$k_{660}\left(\mathrm{~cm} \mathrm{~h}^{-1}\right)$} \\
\cline { 2 - 3 } Baffle frequency $(\mathrm{Hz})$ & $\mathrm{CH}_{4}$ & $\mathrm{SF}_{6}$ \\
\hline 0.6 & $15.5 \pm 0.6$ & $16.7 \pm 0.6$ \\
0.7 & $22.8 \pm 0.9$ & $24.0 \pm 1.0$ \\
0.75 & $25.9 \pm 0.6$ & $25.5 \pm 0.9$ \\
\hline
\end{tabular}

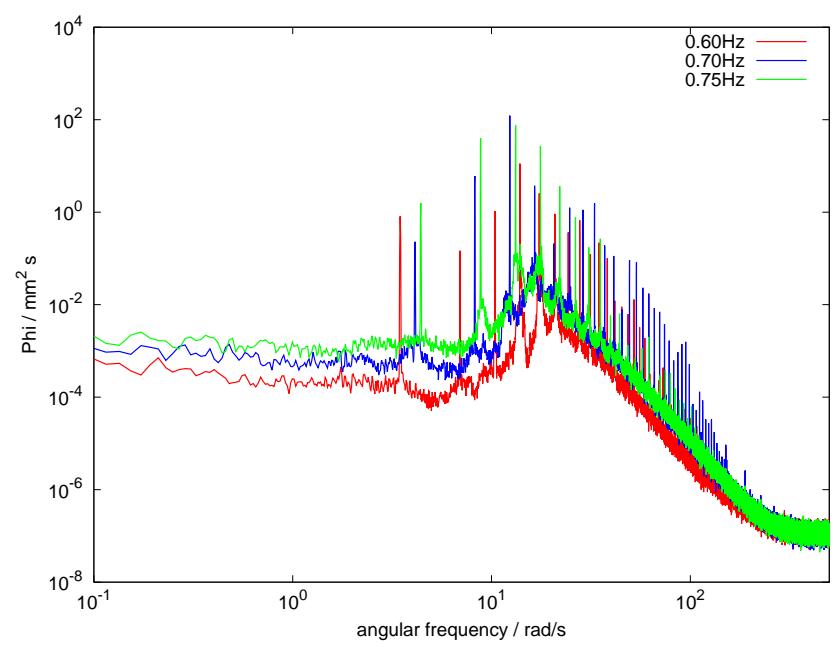

Figure 9. Wave spectra of a typical gas exchange experiment with Milli-Q water. The first peak for each boundary condition corresponds to the respective baffle speed, peaks at higher frequencies to harmonics.

\subsection{Milli-Q experiments}

A number of experiments with Milli-Q water were conducted to validate the experiment and to test the reproducibility. Figure 7 shows the mass balance, i.e. the total amount of gas within the tank, for a typical exchange experiment. Deviations are within the error, proving that the setup is gas-tight, i.e. no gas is lost or acquired during the run.

Estimated values of $k_{660}\left(k_{\mathrm{w}}\right.$ scaled to a Schmidt number of 660) derived from $\mathrm{CH}_{4}$ and $\mathrm{SF}_{6}$ for six different Milli-Q experiments are shown in Fig. 8. Weighted means and standard deviations of these data are summarised in Table 1. For individual experiments the two independent $k_{660}$ estimates show very close agreement; any small discrepancies most likely include uncertainties in the Schmidt number values and the solubility parameterisations. Thus, even in the worst case changes of $2 \mathrm{~cm} \mathrm{~h}^{-1}$ are significant with $95 \%$ probability; for the baffle speed of $0.6 \mathrm{~Hz}$ the significance level is $1.2 \mathrm{~cm} \mathrm{~h}^{-1}$ with $95 \%$ probability. The weighted standard deviation is $4 \%$ for all baffle speeds and both gases.

Wave spectra for a selected experiment are shown in Fig. 9. As expected, the wave energy is higher for higher baffle frequencies. The first peak for each boundary condition corresponds to the respective baffle speed, showing that the baffle 


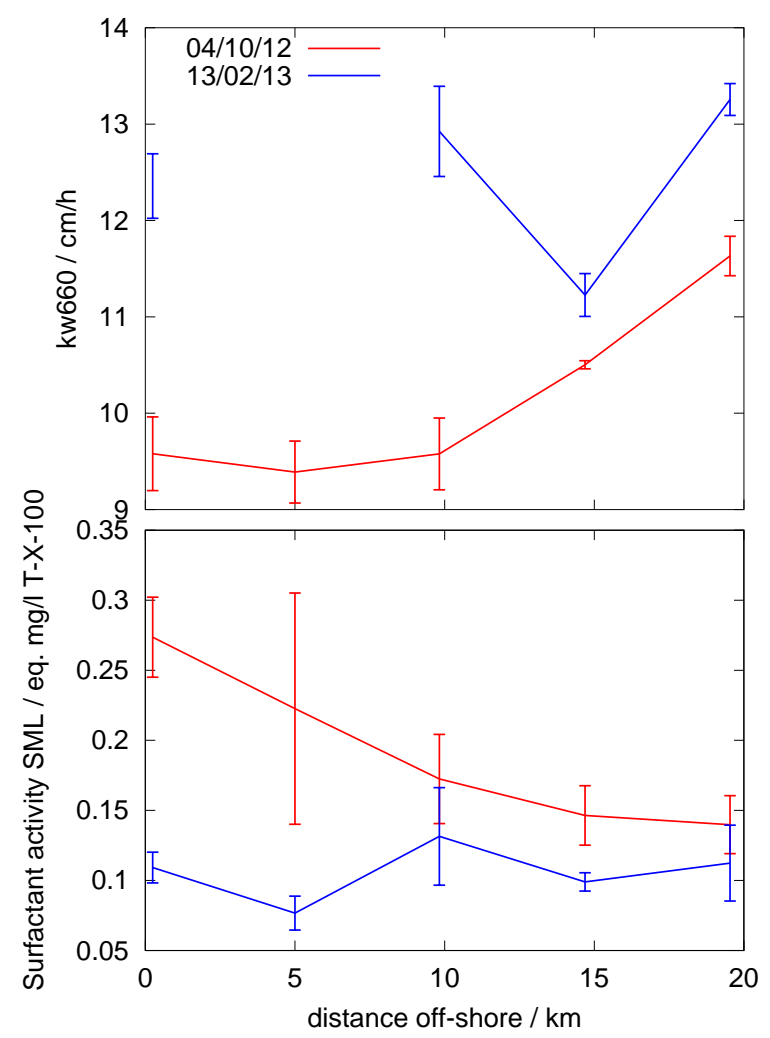

Figure 10. Top: estimated transfer velocities of seawater samples scaled to Schmidt number 660 for two transects in the coastal North Sea off northeast England. Bottom: measured surfactant activity (SA) of the surface microlayer (SML) on transects in the coastal North Sea off northeast England. Results are expressed as equivalent concentration of the calibration surfactant Triton T-X-100.

has a reproducible and stable frequency. Further peaks at higher frequencies are the harmonics caused by reflection and refraction inside the tank.

\subsection{Seawater experiments}

Estimated values of $k_{\mathrm{w}}$ from the coastal North Sea transects, derived from $\mathrm{CH}_{4}$ at a baffle speed of $0.6 \mathrm{~Hz}$, are shown in Fig. 10 (top). For the winter transect (13 February 2013) $k_{\mathrm{W}}$ was between $(12.4 \pm 0.3) \mathrm{cm} \mathrm{h}^{-1}$ (near-shore) and (13.2 \pm $0.2) \mathrm{cm} \mathrm{h}^{-1}$ (off-shore), while corresponding autumn (4 October 2012) values were between $(9.4 \pm 0.3) \mathrm{cm} \mathrm{h}^{-1}$ (nearshore) and (11.6 \pm 0.2$) \mathrm{cm} \mathrm{h}^{-1}$ (off-shore). Comparing these transfer velocities with the surfactant activity (SA) of the SML samples (Fig. 10 bottom) clearly shows a correlation. The spatial and temporal differences in $k_{\mathrm{w}}$ are a function of SA. The spatial gradients in $k_{\mathrm{w}}$ are consistent with a decreasing influence of terrestrially derived surfactants in river outflow with distance offshore. Higher $k_{\mathrm{W}}$ suppression by surfactant during the autumn reflects higher SA arising from primary productivity, whereas lower winter suppression presumably reflects lower SA arising from surfactant degradation processes.

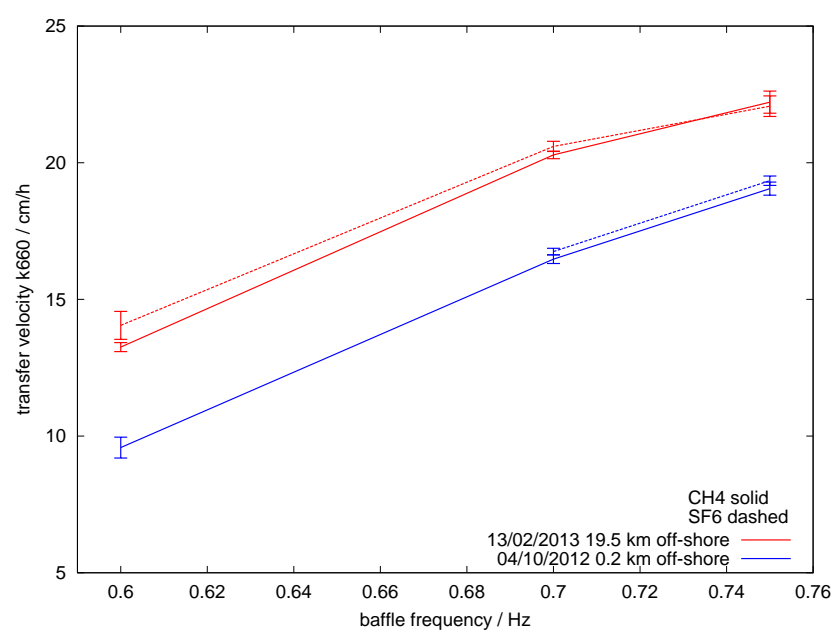

Figure 11. Estimated transfer velocities $k_{\mathrm{W}}$ vs. baffle frequency for the most landwards station of the autumn transect (low $k_{\mathrm{W}}$ ) and the most off-shore station from the winter transect (high $k_{\mathrm{W}}$ ) for $\mathrm{CH}_{4}$ and $\mathrm{SF}_{6}$. Note that for the 4 October 2012 transect, the datum for $\mathrm{SF}_{6}$ at $F=0.6 \mathrm{~Hz}$ is excluded due to chromatography problems for this particular point.

For the most landwards station of the autumn transect (low $k_{\mathrm{W}}$ ) and the most off-shore station from the winter transect (high $k_{\mathrm{w}}$ ), $k_{\mathrm{W}}$ vs. baffle frequency is shown for $\mathrm{CH}_{4}$ and $\mathrm{SF}_{6}$ in Fig. 11. The agreement between the two gases is acceptable, the discrepancies being largely attributable to uncertainties in the Schmidt number parameterisations, with additional small contributions arising from $\mathrm{GC}$ detector drift, which is somewhat larger for $\mathrm{SF}_{6}$ than for $\mathrm{CH}_{4}$. Nevertheless, the observed trends are clearly significant within the analytical error. Our experimental procedures are evidently well suited to examine the relative natural variability of $k_{\mathrm{w}}$ between seawater samples containing varying levels of surfactant.

\section{Conclusions}

We have developed a laboratory gas exchange tank and associated analytical methodology that enables fully automated, routine determination of the gas transfer velocities of $\mathrm{SF}_{6}$, $\mathrm{CH}_{4}$ and $\mathrm{N}_{2} \mathrm{O}$ in natural seawaters under strictly controlled conditions of turbulence. Repeated experiments with Milli-Q water demonstrated a typical measurement accuracy of $4 \%$ for $k_{\mathrm{w}}$. Experiments with natural seawater samples collected on two North Sea coastal transects showed a clear influence of surfactant activity on the strong spatial and temporal gradients in $k_{\mathrm{w}}$ that we observed. During ongoing and planned work, both in the coastal North Sea and in the open ocean, we aim to establish clear relationships between $k_{\mathrm{w}}$, surfactant activity and biogeochemical indices of primary productivity. In so doing we hope to better understand the spatio-temporal variability of $k_{\mathrm{w}}$ and thereby, to contribute valuable new insights into the air-sea gas exchange process. 


\section{Appendix A: Error propagation}

Uncertainties of measured quantities were calculated using Gaussian error propagation. For a quantity $y$ which is a function of $N$ statistically independent variables $x_{i}$ with Gaussian-distributed uncertainties $\sigma_{x_{i}}, i \in 1, \ldots, N$, i.e. $y=$ $y\left(x_{1}, \ldots, x_{N}\right)$, the uncertainty of $y$ is

$\sigma_{y}^{2}=\sum_{i=1}^{N}\left(\frac{\partial y}{\partial x_{i}}\right)^{2} \sigma_{x_{i}}^{2}$.

Application to Eqs. (12) and (13) leads to

$$
\begin{aligned}
\sigma_{B_{n}}^{2} & =\left[\frac{A}{t_{n}-t_{0}} \sum_{j=1}^{n} \frac{t_{j}-t_{j-1}}{\left(V_{\mathrm{w}, 0}-j V_{\mathrm{s}}\right)^{2}}\right]^{2} \sigma_{V_{\mathrm{w}, 0}}^{2} \\
& +\left[\frac{A}{t_{n}-t_{0}} \sum_{j=1}^{n} \frac{j\left(t_{j}-t_{j-1}\right)}{\left(V_{\mathrm{w}, 0}-j V_{\mathrm{s}}\right)^{2}}\right]^{2} \sigma_{V_{\mathrm{s}}}^{2} \\
& +\left(\frac{\alpha A}{V_{\mathrm{a}}^{2}}\right)^{2} \sigma_{V_{\mathrm{a}}}^{2}+\left(\frac{A}{V_{\mathrm{a}}}\right)^{2} \sigma_{\alpha}^{2}
\end{aligned}
$$

and

$$
\sigma_{\chi_{n}}^{2}=\frac{1}{B_{n}^{2}}\left(\frac{1}{D^{2}} \sigma_{D}^{2}+\frac{1}{D_{0}^{2}} \sigma_{D_{0}}^{2}\right)+\left(\frac{\ln \left(\frac{D_{0}}{D}\right)}{B_{n}^{2}}\right)^{2} \sigma_{B_{n}}^{2} .
$$


Acknowledgements. We wish to thank our colleagues in the workshop of the School of Marine Science and Technology at Newcastle for modifications to the basic tank structure and for installing the electronic components, and in the glassblowing workshop in the School of Chemistry at Newcastle for manufacturing the equilibration vessel. We acknowledge and appreciate funding provided by the German Research Foundation in support of K. Schneider-Zapp (DFG research fellowship) and we thank the UK Natural Environment Research Council (NERC) for awarding a NERC small grant NE/IO15299/1 to R. Upstill-Goddard.

Edited by: M. Hoppema

\section{References}

Asher, W. E.: The effects of experimental uncertainty in parameterizing air-sea gas exchange using tracer experiment data, Atmos. Chem. Phys., 9, 131-139, doi:10.5194/acp-9-131-2009, 2009.

Bock, E. J., Hara, T., Frew, N. M., and McGillis, W. R.: Relationship between air-sea gas transfer and short wind waves, J. Geophys. Res., 104, 25821-25831, doi:10.1029/1999JC900200, 1999.

Bullister, J. L., Wisegarver, D. P., and Menzia, F. A.: The solubility of sulfur hexafluoride in water and seawater, Deep-Sea Res. Pt. I, 49, 175-187, doi:10.1016/S0967-0637(01)00051-6, 2002.

Ćosović, B. and Vojvodić, V.: The application of ac polarography to the determination of surface-active substances in seawater, Limnol. Oceanogr., 27, 361-369, 1982.

Crutzen, P. J. and Zimmermann, P. H.: The changing photochemistry of the troposphere, Tellus B, 43, 136-151, doi:10.1034/j.1600-0889.1991.t01-1-00012.x, 1991.

Dlugokencky, E. J., Masarie, K. A., Lang, P. M., and Tans, P. P.: Continuing decline in the growth rate of the atmospheric methane burden, Nature, 393, 447-450, 1998.

Dlugokencky, E. J., Walter, B. P., Masarie, K. A., Lang, P. M., and Kasischke, E. S.: Measurements of an anomalous global methane increase during 1998, Geophys. Res. Lett., 28, 499-502, doi:10.1029/2000GL012119, 2001.

Frew, N. M.: The role of organic films in air-sea exchange, in: The Sea Surface and Global Change, edited by: Liss, P. S. and Duce, R. A., Cambridge University Press, 121-172, 1997.

Garrett, W. D.: Collection of slick-forming materials from the sea surface, Limnol. Oceanogr., 10, 602-605, 1965.

Gašparović, B.: Decreased production of surface-active organic substances as a consequence of the oligotrophication in the northern Adriatic Sea, Estuar. Coast. Shelf Sc., 115, 33-39, doi:10.1016/j.ecss.2012.02.004, 2012.

Goldman, J. C., Dennett, M. R., and Frew, N. M.: Surfactant effects on air-sea gas exchange under turbulent conditions, Deep-Sea Res., 35, 1953-1970, doi:10.1016/0198-0149(88)90119-7, 1988.

Harnisch, J. and Eisenhauer, A.: Natural $\mathrm{CF}_{4}$ and $\mathrm{SF}_{6}$ on Earth, Geophys. Res. Lett., 25, 2401-2404, doi:10.1029/98GL01779, 1998.

Harris, F. J.: On the use of windows for harmonic analysis with the discrete Fourier Transform, in: Proceedings of the IEEE, Vol. 66$1,1978$.

IPCC: Climate Change 2007 - The Physical Science Basis: Working Group I Contribution to the Fourth Assessment Report of the IPCC, Cambridge University Press, Cambridge, UK and New York, NY, USA, 2007.
Jähne, B.: Air-sea gas exchange, in: Encyclopedia Ocean Sciences, edited by: Steele, J. H., Turekian, K. K., and Thorpe, S. A., 34343444, Elsevier, doi:10.1016/B978-012374473-9.00642-1, 2009.

Khalil, M.: Atmospheric Methane: Sources, Sinks and Role in Global Change, Springer, New York, 1993.

Khatiwala, S., Primeau, F., and Hall, T.: Reconstruction of the history of anthropogenic $\mathrm{CO}_{2}$ concentrations in the ocean, Nature, 462, 346-349, doi:10.1038/nature08526, 2009.

McKenna, S. P. and McGillis, W. R.: The role of free-surface turbulence and surfactants in air-water gas transfer, Int. J. Heat Mass Tran., 47, 539-553, 2004.

Nevison, C. D. and Holland, E.: A reexamination of the impact of anthropogenically fixed nitrogen on Atmospheric $\mathrm{N}_{2} \mathrm{O}$ and the stratospheric $\mathrm{O}_{3}$ layer, J. Geophys. Res., 102, 25519-25536, doi:10.1029/97JD02391, 1997.

Nightingale, P., Malin, G., Law, C. S., Watson, A. J., Liss, P. S., Liddicoat, M. I., Boutin, J., and Upstill-Goddard, R. C.: In situ evaluation of air-sea gas exchange parameterizations using novel conservative and volatile tracers, Glob. Biogeochem. Sci., 14, 373-387, doi:10.1029/1999GB900091, 2000.

Phillips, O. M.: The Dynamics of the Upper Ocean, Cambridge University Press, New York, 1980.

Prinn, R., Cunnold, D., Rasmussen, R., Simmonds, P., Alyea, F., Crawford, A., Fraser, P., and Rosen, R.: Atmospheric emissions and trends of nitrous oxide deduced from 10 years of ALE-GAGE data, J. Geophys. Res.-Atmos., 95, 18369-18385, doi:10.1029/JD095iD11p18369, 1990.

Richter, K. and Jähne, B.: A laboratory study of the Schmidt Number dependency of air-water gas transfer, in: Proc. 6th Int. Symp. Gas Transfer at Water Surfaces, 2010.

Rigby, M., Prinn, R. G., Fraser, P. J., Simmonds, P. G., Langenfelds, R. L., Huang, J., Cunnold, D. M., Steele, L. P., Krummel, P. B., Weiss, R. F., O’Doherty, S., Salameh, P. K., Wang, H. J., Harth, C. M., Mühle, J., and Porter, L. W.: Renewed growth of atmospheric methane, Geophys. Res. Lett., 35, L22805, doi:10.1029/2008GL036037, 2008.

Salter, M. E., Upstill-Goddard, R. C., Nightingale, P. D., Archer, S. D., Blomquist, B., Ho, D. T., Huebert, B., Schlosser, P., and Yang, M.: Impact of an artificial surfactant release on air-sea gas fluxes during Deep Ocean Gas Exchange Experiment II, J. Geophys. Res., 116, C11016, doi:10.1029/2011JC007023, 2011.

Schneider-Zapp, K., Salter, M. E., Mann, P. J., and UpstillGoddard, R. C.: Technical Note: Comparison of storage strategies of sea surface microlayer samples, Biogeosciences, 10, 4927-4936, doi:10.5194/bg-10-4927-2013, 2013.

Takahashi, T., Sutherland, S. C., Wanninkhof, R., Sweeney, C., Feely, R. A., Chipman, D. W., Hales, B., Friederich, G., Chavez, F., Sabine, C., A., W., Bakker, D. C. E., Schuster, U., N., M., Yoshikawa-Inoue, H., Ishii, M., Midorikawa, T., Nojiri, Y., Körtzinger, A., Steinhoff, T., Hoppema, M., Olafsson, J., Arnarson, T. S., Tilbrook, B., Johannessen, T., Olsen, A., Bellerby, R., Wong, C. S., Delille, B., Bates, N. R., and de Baar, H. J. W.: Climatological mean and decadal change in surface ocean $\mathrm{pCO}_{2}$, and net sea-air $\mathrm{CO}_{2}$ flux over the global oceans, Deep-Sea Res. Pt. II, 56, 554-577, doi:10.1016/j.dsr2.2008.12.009, 2009. 
Tayler, J. R.: An introduction to error analysis: the study of uncertainties in physical measurements. 2nd edition, University Science Books, Sausalito, 1996.

Upstill-Goddard, R. C.: Air-sea gas exchange in the coastal zone, Estuar. Coast. Shelf S., 70, 388-404, doi:10.1016/j.ecss.2006.05.043, 2006.

Upstill-Goddard, R. C.: The production of trace gases in the estuarine and coastal environment, in: Treatise on Estuarine and Coastal Science, edited by: Wolanski, E. and McLusky, D., 271309, Academic Press, London, 2011.

Upstill-Goddard, R. C., Watson, A. J., Liss, P. S., and Liddicoat, M. I.: Gas transfer velocities in lakes measured with $\mathrm{SF}_{6}$, Tellus B, 42, 364-377, doi:10.1034/j.1600-0889.1990.t013-00006.x, 1990.

Upstill-Goddard, R. C., Rees, A. P., and Owens, N. J. P.: Simultaneous high-precision measurements of methane and nitrous oxide in water and seawater by single phase equilibration gas chromatography, Deep-Sea Res. Pt. I, 43, 1669-1682, doi:10.1016/S0967-0637(96)00074-X, 1996.

Upstill-Goddard, R. C., Frost, T., Henry, G. R., Franklin, M., Murrell, J. C., and Owens, N. J. P.: Bacterioneuston control of air-water methane exchange determined with a laboratory gas exchange tank, Global Biogeochem. Cy., 17, 19.1-19.15, doi:10.1029/2003GB002043, 2003.

Wanninkhof, R.: Relationship between wind speed and gas exchange over the ocean, J. Geophys. Res., 97, 7373-7382, doi:10.1029/92JC00188, 1992.

Wanninkhof, R., Asher, W., Weppernig, R., Chen, H., Schlosser, P., Langdon, C., and Sambrotto, R.: Gas transfer experiment on Georges Bank using two volatile deliberate tracers, J. Geophys. Res., 98, 20237-20248, 1993.
Wanninkhof, R., Hitchcock, G., Wiseman, W. J., Vargo, G., Ortner, P. B., Asher, W., Ho, D. T., Schlosser, P., Dickson, M. L., Masserini, R., Fanning, K., and Zhang, J. Z.: Gas exchange, dispersion and biological productivity on the West Florida Shelf: results from a Lagrangian tracer study, Geophys. Res. Lett., 24, 1767-1770, 1997.

Watson, A. J., Upstill-Goddard, R. C., and Liss, P. S.: Air-sea gas exchange in rough and stormy seas measured by a dual tracer technique, Nature, 349, 145-147, 1991.

Weiss, R. F. and Price, B. A.: Nitrous oxide solubility in water and seawater, Mar. Chem., 8, 347-359, doi:10.1016/03044203(80)90024-9, 1980.

Welch, P. D.: The use of fast Fourier transform for the estimation of power spectra: a method based on time averaging over short, modified periodograms, IEEE Transactions on Audio and Electroacoustics, 15, 70-73, doi:10.1109/TAU.1967.1161901, 1967.

Wiesenburg, D. A. and Guinasso, N. L.: Equilibrium solubilities of methane, carbon monoxide, and hydrogen in water and sea water, J. Chem. Eng. Data, 24, 356-360, doi:10.1021/je60083a006, 1979.

Wurl, O., Wurl, E., Miller, L., Johnson, K., and Vagle, S.: Formation and global distribution of sea-surface microlayers, Biogeosciences, 8, 121-135, doi:10.5194/bg-8-121-2011, 2011.

Zutić, V. B., Ćosović, E., Marčenko, E., and Bihari, N.: Surfactant production by marine phytoplankton, Mar. Chem., 10, 505-520, doi:10.1016/0304-4203(81)90004-9, 1981. 